Journal of Biomedical and Pharmaceutical Research

Available Online at www.jbpr.in

CODEN: - JBPRAU (Source: - American Chemical Society)

PubMed (National Library of Medicine): ID: (101671502)

Volume 8, Issue 3: May-June: 2019, 24-28

Original Research Article
ISSN (Online): 2279-0594

ISSN (Print): 2589-8752

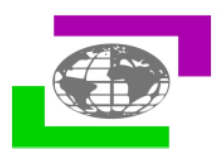

\title{
PHARMACOEPIDEMIOLOGICAL STUDY OF NON-STEROIDAL ANTI-INFLAMMATORY DRUGS AND ITS EFFECTS ON CARDIOVASCULAR SYSTEM AMONG SELECTED AREAS OF CHITRADURGA.
}

\author{
Tejaswini S.M.*, Bharathi DR, Nataraj GR, Akza K Alex, Adarsh Mathew \\ SJM College of Pharmacy, Chitradurga-577502
}

Article Info: Received 20 April 2019; Accepted 17 May. 2019

DOI: https://doi.org/10.32553/jbpr.v8i3.598

Address for Correspondence: Tejaswini S.M., SJM College of Pharmacy, Chitradurga-577502

Conflict of interest statement: No conflict of interest

\section{ABSTRACT:}

Background: Nonsteroidal anti-inflammatory drugs (NSAIDs) are used worldwide to treat pain and inflammation.

Non-steroidal anti-inflammatory drugs (NSAIDs) are a broad class of agents with analgesic and antiinflammatory properties that inhibit the two recognized iso enzymes of prostaglandin $\mathrm{G} / \mathrm{H}$ synthase (also known as cyclo -oxygenase (COX))-namely, COX 1 and COX 2.

It is generally accepted that oral non-steroidal anti-inflammatory drugs (NSAIDs) can increase the risk of acute myocardial infarction. Randomized controlled trials of NSAIDs have been of limited use for assessing this rare adverse event, as they had small cohorts and poor generalizability. The trials excluded those at highest cardiovascular risk or with established cardiovascular disease.

Objectives: 1 . To assess the various classes of NSAID'S giving rise to cardiovascular risks. 2. To assess the prevalence of NSAID's induced various cardiovascular risks.

Materials and Methods: The study was carried out in selected areas of Chitradurga District.

Results: 1. In our study, subjects who were having CVS risks were found to be the major users of Selective cox-2 inhibitor 20(27.7) followed by preferential cox-2 inhibitor 8(11.1)) and phenyl acetic acid 6(8.3).

2. Among 401 subjects, 72 subjects were diagnosed as cardiovascular problem. The prevalence of NSAIDs induced cardiovascular problem was found to be $18 \%$

Conclusion: Our study concluded that prevalence of cardiovascular risk due to administration of NSAIDs more in rural areas than in urban areas.

Key words: NSAIDs, CVS risks, Prevalence.

\section{INTRODUCTION}

\section{Need for the study}

Non-steroidal anti-inflammatory drugs (NSAIDs) are the most commonly used drugs for the treatment of pain, inflammation. 29 millions of people are found to be regular users of NSAIDs in USA. Still, it is having severe side effects like hypertension, renal failure, gastrointestinal bleeding, bronchospasm and cardiovascular complications such as myocardial infarction, stroke and congestive heart failure. 1
As NSAIDs have an analgesic effect it is used in the treatment of osteoarthritis or Rheumatoid Arthritis. Many evidences has shown cardiovascular risks in patients who are taking NSAIDs for osteoarthritis and rheumatoid arthritis. 2

NSAIDs are being repeatedly used in all age groups, in that most $70 \%$ is used by elderly patients. NSAIDs may cause gastrointestinal toxicity and the risk of upper gastrointestinal complications including ulceration. 3

The effect of NSAIDs on blood pressure has been examined in clinical trials, but not in observational 
Tejaswini S.M. et al., Journal of Biomedical and Pharmaceutical Research

studies, henceforth it is very important to know the effect of NSAIDs. 4

Since NSAIDs are most frequently used medicaments in the world, it is being available as an over- the -counter medication too. 5

\section{Materials and Methods}

- Study Design: A Prospective observational Study.

- Study Site: The study was carried out in selected areas of chitradurga.

- Study Period: The study was conducted for a period of 10 months.

\section{Inclusion Criteria}

- Both the genders.

- Patients of age group between 45-75.

- Patients who are having comorbid conditions with cardiovascular diseases

- Patients with hypertension and nonhypertensive patients.

Exclusion Criteria

- Bed ridden patients.

- The patients who are disoriented.

\section{Source of Data}

- Demographic details of the patient.

- Treatment chart.

- Medical history.

- Medication history.

Study Procedure:
- The study was started after obtaining the ethical clearance of Institutional Ethics Committee (IEC).

Ref:No.SJMCP/IEC/36/2017-18

- Once the patient's satisfied above study criteria were recruited into the study.

- Before starting the study the patients were given Informed Consent Form which will be duly filled by the patient or patient's relatives after explaining the importance of the study.

- A prospective observational study was carried out in all the patients satisfying the inclusion criteria

- Sample subjects enrolled into the study on randomization based on convenience.

- The patients were recruited from eight different localities from Chitradurga district comprising of four from Rural and four from Urban areas.

- The demographics data was collected in a suitably designed data collection form and other important relevant data was collected from validated self-designed questionnaire from one to one interaction with the subjects

\section{Statistical Analysis}

1. Data have been analyzed by descriptive statistics by using Social Programme Scientific Software (SPSS) 24.

2. Data was analysed by descriptive statistics method and one sample t test

\section{Results}

Table 1: Distribution of Cardiovascular risks subjects according to their usage of NSAIDs

Among the subjects, who were having CVS risks were found to be the users of following class of NSAIDs

\begin{tabular}{|l|l|l|l|l|l|}
\hline \multirow{2}{*}{ Drugs used $(\mathrm{n}=72)$} & \multicolumn{5}{|c|}{ Cardiovascular disorders } \\
\cline { 2 - 6 } & $\mathrm{HT}$ & $\mathrm{MI}$ & $\mathrm{CCF}$ & $\mathrm{HS}$ & Total \\
\hline SALI & $3(04.1)$ & $1(1.3)$ & 0 & 0 & $4(5.5)$ \\
\hline PAP & $4(5.5)$ & $1(1.3)$ & 0 & 0 & $5(6.9)$ \\
\hline PA & $4(5.5)$ & $1(1.3)$ & $1(1.3)$ & 0 & $6(8.3)$ \\
\hline OXI & $1(1.3)$ & $1(1.3)$ & $1(1.3)$ & 0 & $3(4.1)$ \\
\hline PAD & $01(1.3)$ & $1(1.3)$ & 0 & 0 & $2(2.7)$ \\
\hline FEN & $01(1.3)$ & 0 & 0 & 0 & $1(1.3)$ \\
\hline IND & $01(1.3)$ & 0 & 0 & 0 & $1(1.3)$ \\
\hline P COX-2 INH & $03(4.1)$ & $02(2.7)$ & $02(2.7)$ & $01(1.3)$ & $8(11.1)$ \\
\hline S COX-2 INH & $6(8.3)$ & $4(5.5)$ & $6(8.3)$ & $4(5.5)$ & $20(27.7)$ \\
\hline Total & $24(33.3)$ & $11(15.2)$ & $10(13.8)$ & $5(6.9)$ & $50(100)$ \\
\hline
\end{tabular}


Tejaswini S.M. et al., Journal of Biomedical and Pharmaceutical Research

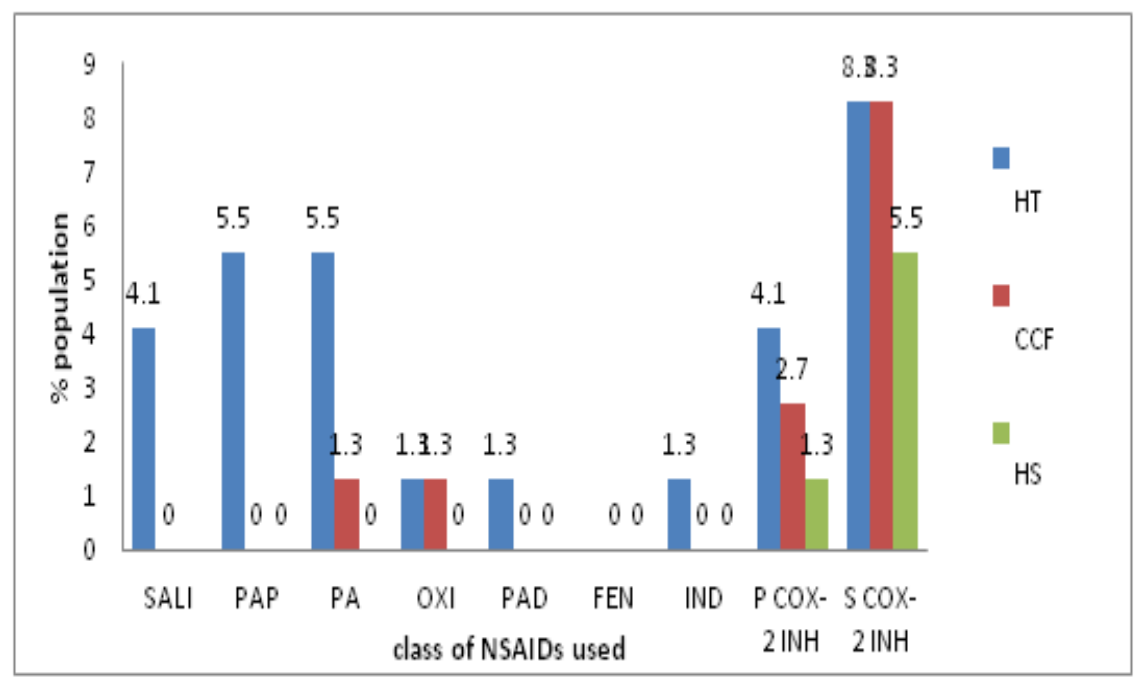

Fig. 1: Distribution of Cardiovascular risks subjects according to their usage of NSAIDs

Distribution of subjects having history of CVS risks.

In this study we found that Hypertension 66(16.4) as major CVS related issue, others were negligible. Results are shown in table 2 and graphically represented in figure 2.

Table 2: Distribution of subjects according to Cardiovascular Risk related Medical History ( $N=401)$

\begin{tabular}{|l|l|l|l|}
\hline \multirow{2}{*}{ Cardiovascular Risks } & \multicolumn{3}{|c|}{ Frequency (\%) } \\
\cline { 2 - 4 } & Rural Subjects & Urban Subjects & Total \\
\hline Hypertension & $36(17.7)$ & $30(15.1)$ & $66(16.4)$ \\
\hline Myocardial Infraction & $2(0.9)$ & $2(1.0)$ & $4(0.99)$ \\
\hline Congestive Cardiac Failure & $0(0)$ & $1(0.5)$ & $1(0.5)$ \\
\hline Heart surgery & $0(0)$ & $1(0.5)$ & $1(0.5)$ \\
\hline Total & $203(100)$ & $198(100)$ & $401(100)$ \\
\hline
\end{tabular}

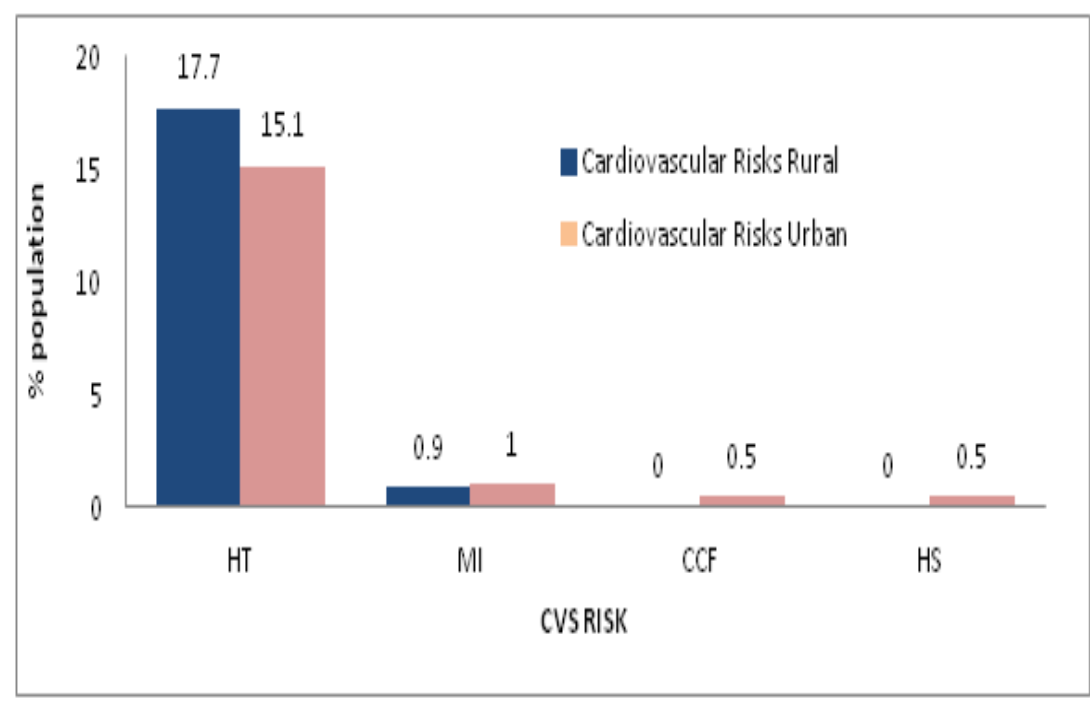

Fig. 2: Distribution of subjects according to Cardiovascular Risk related Medical History 
Tejaswini S.M. et al., Journal of Biomedical and Pharmaceutical Research

\section{Prevalence assessment:}

A total of 401 subjects who are taking NSAIDs, with or without comorbid were considered for the study. Among them 72 subjects were with cardiovascular risk. The data of 72 cardiovascular risk subjects were analysed and presented as follows

\section{Prevalence assessment:}

A total of 401 subjects who are taking NSAIDs, with or without comorbid were considered for the study. Among them 72 subjects were with cardiovascular risk. The data of 72 cardiovascular risk subjects were analysed and presented as follows

\section{PREVALENCE OF CARDIOVASCULAR DISORDERS AMONG NSAIDS USERS}

Among 401 subjects,72 subjects were diagnosed as cardiovascular problem. The prevalence of NSAIDs induced cardiovascular problem was found to be $18 \%$

Total number of NSAIDs users enrolled in the study $(\mathrm{N})=401$

Total number of NSAIDs users with cardiovascular risk enrolled in the study $=72$

Prevalence $=$ Number of population with disease at a given time $\times 100$

Total number of population at a given time

$$
\begin{aligned}
& =72 / 40 \times 100 \\
& =18 \%
\end{aligned}
$$

Prevalence of NSAID induced cardiovascular problems is $18 \%$ that is 1 in every 22 members will be effected with cardiovascular risks

Table 3: Determination of One sample $t$ test

\begin{tabular}{|l|l|l|l|}
\hline Details & Frequency (\%) & t value & Level of significance \\
\hline Patients developed cardiovascular disorders & $72(17.96)$ & \multirow{2}{*}{20.78} & $\begin{array}{l}20.78 \\
* *\end{array}$ \\
\cline { 1 - 2 } Patients without cardiovascular diseases & $329(82.04)$ & & \\
\hline
\end{tabular}

$* * p<0.005$

One sample $t$-test showed significant, as $t$ value $(t=20.78)$ with level of significance

$\mathrm{p}=0.002(<0.01)$

\section{Discussion}

In present study, subjects who were having cvs risks were found to be the major users of Selective cox-2 inhibitor 20(27.7) followed by preferential cox-2 inhibitor 8(11.1)) and phenyl acetic acid 6(8.3) where as Dong $Y$ et al conducted a similar study on Comparative cardiovascular safety of nonsteroidal anti-inflammatory drugs in patients with hypertension: a population-based cohort study and found that patients initiating selective COX-2- NSAIDs (65\%) was prescribed more commonly than etoricoxib (35\%). Among patients initiating non selective NSAIDs ( $N=52880)$, phenyl acetic acid (34\%), mefenamic acid (22\%) and ibuprofen (15\%) were most commonly prescribed;.19 it was similar to our study. 6

As per current study, CVS rsiks subjects majorly preferred class of NSAIDs was selective COX-2 inhibitors followed by preferential COX-2 inhibitors and Phenyl acetic acid derivatives, may be because of trust and compatibility of the subjects with those drugs. Hence null hypothesis rejected and alternative hypothesis accepted.

In our study among the study participants, prevalence of hypertension and other CVS risks factors were with $18 \%$. Whereas study done by 
Saxena T et al., on Prevalence of hypertension in a rural community of coastal Karnataka: a cross sectional study and they found that prevalence of hypertension among study participants was $18 \%$ was similar to our study .7

According to this study, the prevalence of hypertension among study participants is $18 \%$ as one sample $\mathrm{t}$ - test showed significant, as $\mathrm{t}$ value $(t=20.78)$ with level of significance $p=0.002(<0.01)$ hence null hypothesis is rejected and alternative hypothesis is accepted.

\section{Conclusion}

- Our study concluded that prevalence of cardiovascular risk due to administration of NSAIDs more in rural areas than in urban areas.

- Many subjects were unaware about this CVS disorder due to the usuage of NSAIDs

- Null hypothesis rejected alternative hypothesis accepted as study was defined to assess cvs disorder due to the usage of NSAIDs.

- One sample $t$-test showed significant as $t$ value $(\mathrm{t}=20.78 \quad$ with level of significance $\mathrm{p}=0.002(<0.005)$

- In our study, subjects who were having cvs risks were found to be the major users of Selective cox-2 inhibitor 20(27.7) followed by preferential cox-2 inhibitor 8(11.1)) and phenyl acetic acid 6(8.3)

- Among 401 subjects,72 subjects were diagnosed as cardiovascular problem. The prevalence of NSAIDs induced cardiovascular problem was found to be $18 \%$

\section{Acknowledgement}

It is a pleasure and privilege to express my deep sense of thanks and indebtedness to the management of SJM College of Pharmacy Karnataka, Dr. Bharathi D.R, Principal SJM College of Pharmacy and Mr.Nataraj GR for giving the consent and facilities to carry out this work.

\section{References:}

1. Landefeld K, Gonzales H, Sander GE. Hypertensive crisis: The causative effects of non-steroidal anti-inflammatory drugs. J Clin case rep 2016;6(9):1-3.

2. Nissen SE, Yeomans ND, Solomon DH, Luscher TF, Libby P, Husni ME, et al. Cardiovascular Safety of Celecoxib, Naproxen, or Ibuprufen for Arthritis. The New England Journal of Medicine 2018;375(26):2519-29.

3. Schellack N. An Overview of gastropathy induced by nonsteroidal anti-inflammatory drugs. S Afr Pharm J 2012;79 (4):12-18.

4. Aljadhey $H$, Wanzhu Tu, Hansen R A, Blalock S.J, Brater $D$ and Murray M D. Comparitive effects of non steroidal anti-inflammatory drugs (NSAIDs) on blood pressure in patients with hypertension.BioMed Central 2012;1-10.

5. Sager P, Heilbraun J, Turner JR, Gintant G, Geiger MJ, Kowey PR. Cardiac Safety Research Consortium 2013;165:477-88.

6. Goldstein J, Cryer B. Gastrointestinal injury associated with NSAID use: a case study and review of risk factors and preventative strategies. Drug, Healthcare and Patient Safety. 2015:31. urnal

7. G C, Siddique A, D.R B. Assessment of Medication Therapy of Cardiovascular Diseases Patients in Intensive Care Unit". 2016;1-30.

8. Schmidt $M$, Sorensen $H T$, Pedersen $L$. Diclofenac use and cardiovascular risks: series of nationwide cohort studies. The bmj 2018;362:1-9.

9. Lin TC, Solomon DH, Tedeschi SK, Yoshidak, Yang YHK etal. Comparative Risk of Cardiovascular Outcomes Between Topical and Oral Nonselective NSAIDs in Taiwanese Patients With Rheumatoid Arthritis. Journal of the American Heart Association 2017;6:(11)19.

10. Tamargo J, Rosano G, Walther T, Duarte J, Niessner A etal. Gender differences in the effects of cardiovascular drugs. European Heart Journal 2017;3(3)163-82.

11. Thone K, Kovhorst B, Schinik T. Non-Steroidal Anti-Inflammatory Drug Use and the Risk of Acute Myocardial Infarction in the General German Population: A Nested Case-Control Study. Drugs - Real World Outcomes 2017;4(3):127-37.

12. Sevinsky RT, Stewart DW, Harirforoosh S. Nonsteroidal anti-inflammatory drugs: Is there a link between cardiovascular and renal adverse effects?. Journal of Integrative Nephrology and Andrology 2017;4(1):1-2. 